NBER WORKING PAPER SERIES

\title{
SURVEY RESPONSE VARIATION IN THE \\ CURRENT POPULATION SURVEY
}

James M. Poterba

Lawrence H. Summers

Working Paper No. 1109

NATIONAL BUREAU OF ECONOMIC RESEARCH

1050 Massachusetts Avenue

Cambridge MA 02138

April 1983

We are grateful to the NBER for financial support and to Norman Bowers of the Bureau of Labor Statistics for comments on an earlier draft. The research reported here is part of the NBER's research program in Labor Studies. Any opinions expressed are those of the authors and not those of the National Bureau of Economic Research. 
NBER Working Paper 非1109

April 1983

Survey Response Variation in

the Current Population Survey

\section{ABSTRACT}

This paper investigates the problem of response and coding errors in the Current Population Survey. It draws upon a potentially rich source of information for verifying survey answers, a three month matched sample of CPS respondents, to analyze whether individuals' questionnaire responses in adjacent months are mutually consistent.

We focus primarily on reported durations of unemployment spells. For j.ndividuals who were coded as unemployed jn two consecutive months and who experienced no intervening labor market withdrawal or employment, their reported duration in the second interview should exceed the first interview duration by about four weeks. However, this is not what survey responses show. In more than three quarters of all cases, reported durations in successive months are logically inconsistent. The reporting problem is not confined to spell durations. In 25 percent of all cases, the professed reason for unemployment changes as the unemployment spell progresses. Furthermore, analysis of labor force entrants shows that reported changes in labor force status between unemployment and not-in-the labor force are not reliable guides to actual behavior.

We conclude that reported durations of unemployment, and to a lesser extent, reasons for unemployment, may be very misleading indicators of future behavior. Econometric analyses which focus on changes in individual behavior over time are likely to be badly flawed by spurious changes due to reporting errors. These problems with the Current Population Survey, one of the best sample surveys available, may suggest far greater difficulties in interpreting other sources of panel data.

James $M$. Poterba Department of Economics Massachusetts Institute of Technology

Cambridge, MA 02139
Lawrence H. Summers Department of Economics Massachusetts Institute of Technology

Cambridge, MA 02139 
Survey Response Variation in the Current Population Survey

by

James M. Poterba and Lawrence H. Summers

The Current Population Survey is one of the principal sources of data about labor markets in the U.S. economy. It has been used in numerous investigations of unemployment, since it provides descriptive information about the characteristics of jobless workers and about their unemployment experience. The duration of unemployment spells, and the factors affecting reported unemployment spell lengths, have been subject to particularly intensive study. A substantial body of work has examined how public policies can affect the time which workers spend in unemployment. Previous research has also analyzed how the reason for an individual's entry into unemployment affects his subsequent unemployment experience.

Although major policy recommendations are often based upon analyses of data from the CPS and other surveys, relatively little is known about the frequency of survey response errors and their possible implications for empirical research. CPS Reinterview surveys provide some indication of response variation and their results have been analyzed by statisticians. The Reinterview Survey helps to determine whether individuals consistently answer questions in a particular survey month, but it does not indicate

*After completing this paper we became aware of closely related research by Bowers and Horvath (undated). 
whether individuals provide logically consistent survey responses in different months. The recent advent of panel data sets containing information on survey participants in several consecutive months makes the second question particularly important. Do individuals answer similar questions in similar ways on different surveys? This paper draws upon a potentially rich source of information for verifying survey answers, a three month matched sample of CPS respondents, to analyze whether individuals' questionnaire responses are mutually consistent.

Our results are very troubling. Reported unemployment durations in successive months are logically inconsistent for three out of four survey respondents. In 25 percent of all cases, the professed reason for unemployment changes as the unemployment spell progresses. Furthermore, analysis of the reports of labor force entrants suggests that reported changes in labor force status between unemployment and not-in-the-labor force are not reliable guides to actual behavior.

Several conclusions follow from our analysis. Reported durations of unemployment, and to a lesser extent, reasons for unemployment, may be misleading indicators of future behavior. Analyses which focus on changes in individual behavior over time are likely to be badly flawed by spurious changes due to reporting errors. The character of the data gathered in the CPS, and the procedures used in administering the survey, make response and coding errors less likely in this data source than in many others. Further investigation of the reliability of other frequently used sources of economic data may be warranted. Future research should also examine improvements in survey techniques to minimize response errors, and the development of statistical techniques to treat them. 
Our analygis is divided into four parts. Section I reviews evidence from the Reinterview Survey on individuals' reported labor market status. Section II examines the consistency across time of reported unemployment durations and considers the salience of the unemployment/not in the labor force (NILF) distinction. Section III presents evidence on the consistency over time of individuals' reported reasons for unemployment. The paper's final section considers the implications of our results for empirical research in labor economics, usjing both the CPS and other data sets.

\section{Employment Status Misreporting}

Reporting errors are a substantial problem in the CPS. The incidence of errors due to response and coding mistakes is well documented by the Census Bureau's Reinterview Surveys, which reinterview a subsample of the households jncluded in each month's CPS.1 These secondary interviews typjcally occur about a week after the original survey. Respondents are asked, however, to describe their activities in the preceeding week. In some cases, the "non-reconciled" component of the Reinterview Survey, there is no attempt to determine which, if either, of two different responses on the original and reinterview surveys is correct. However, for the "Reconciled" subgroup of the Reinterview Survey which typically constitutes about one third of the reinterviewed households, the second interviewer actually compares the responses on the first survey with the reinterview answers. Then, before leaving the household, he attempts to determine which, if either, of any conflicting

1 See Graham (1974), Woltman and Schreiner (1979), and Census Bureau Technical Report \#19 (1969). 
responses is correct. The Reinterview responses for those in the reconciled subsample, therefore, are the "truth" as determined by the second interviewer.

The reconciled Reinterview Surveys permit analysis of employment status coding errors. Table I shows the fraction of individuals in each labor market category, after reconciliation, by their category on the first survey. While most of the employed CPS respondents are correctly classified, a substantial fraction of the unemployed individuals are reported in other categories. Ten percent of the truly unemployed were classified as not in the labor force (NILF) on the first survey. A further 3.6 percent were recorded as employed. The accuracy of responses by those truly out of the labor force was also quite high, with 99.2 percent correctly classified. There is some evidence that the mismeasurement problem is greater for women than for men.

The finding that many unemployed individuals are misclassified is important for studies of unemployment dymamics. If nearly fifteen percent of unemployed individuals are incorrectly classified in a given month, then many of the transitions between labor force states may be spurious. Studies of labor market behavior based on the Gross Flows data or investigations using panel data from the CPS may therefore be subject to substantial eтror. ${ }^{2}$

The table suggests that there may be confusion between the states of "unemployment" and "not in the labor force". As we show later, many

\footnotetext{
1 This procedure fails to detect those individuals who report consistent, but incorrect, responses in both months.

2 Poterba and Summers (1983a) discuss methods of adjusting BLS gross-flows data based on estimated response error probabilities.
} 
TABLE I

Employment Status

Mj.sclassifj.cation Probabiliti.es

Calculated Re-interview Error Probabilities

\begin{tabular}{|c|c|c|c|}
\hline \multirow[t]{2}{*}{ True State } & \multicolumn{3}{|c|}{ Recorded State } \\
\hline & Fmployed & Unemployed & NILF \\
\hline Enployed & .9905 & .0016 & .0079 \\
\hline Unemployed & .0356 & .8602 & .1041 \\
\hline \multirow[t]{2}{*}{ NILF } & .0053 & .0025 & .9923 \\
\hline & \multicolumn{3}{|c|}{ MEN } \\
\hline Employed & .9922 & .0013 & .0065 \\
\hline Unemployed & .0474 & .8720 & .0806 \\
\hline \multirow[t]{2}{*}{ NILF } & .0062 & .0048 & .9890 \\
\hline & \multicolumn{3}{|c|}{ WOMEN } \\
\hline Enployed & .9892 & .0019 & .0089 \\
\hline Unemployed & .0194 & .8442 & .1363 \\
\hline NILF & .0049 & .0015 & .9936 \\
\hline & & $N=3750$ & \\
\hline
\end{tabular}

Source: Tables were computed from "General Labor Force Status in the CPS Reinterview by Labor Force Status in the Original Interview, Both Sexes, Total, After Reconciliation", May, 1976 provided from unpublished records at the Burau of the Census. 
indjviduals whose labor market status is U-NILF-U report themselves as experiencing one ongoing spell of unemployment. While the Reinterview Survey reveals that only one quarter of one percent of individuals orj.ginally classified as NILF are actually unemployed, this is because many individuals are genuinely not in the labor force and are rather unlikely to be experiencing an unemployment spell. However, conditional upon having been unemployed the month before, the measurement error rates for the NILF category may be large -- far larger than those in our table. 1

Flinn and Heckman (1982a) argue that the states of unemployment and NILF are well-defined and distinct. They draw evidence from the clear differences in models explaining the probability of someone who is unemployed, and of someone who is NILF, becoming employed. However, this evidence is not relevant to understanding whether a large fraction of those who are unemployed drift in and out of the "NILF" category with little or no change in behavior. The explanation of Heckman and Flinn's finding is that there are a large number of individuals, classified as NILF, who are not casual entrants to the labor force. Many persons are disabled, retired, or otherwise unfit or unable to work. They are conceptually distinct from the unemployed, who are searching for work. A small fraction of NILF respondents, but a substantial fraction of those who were unemployed in the preceding month, may actually be searching for work and ready to accept a job. They are the miscategorized workers on whom we focus.

\footnotetext{
1 Poterba and Summers (1983b) develop analytical procedures for studying labor market transitions when some responses are measured with error.
} 


\section{Reported Unemployment Spell Durations}

The Current Population Survey interviews indjididuls in several consecutive months, and the CPS match files contain data on all interviews with a group of survey participants. These data may be used to examine month-to-month changes in individuals' reported unemployment spell durations. Survey respondents who report that they are unemployed are asked how many weeks they have been "without a job and looking for work". If individuals accurately reported their labor market experience, then the reported unemployment spell duration in the second of two consecutive CPS interviews should exceed the first reported duration by four or five weeks. 1

We obtained data on survey participants who were unemployed in May 1976, and interviewed again in June 1976. These data were used to compute the difference between each individual's reported unemployment spell durations in May and June:

$$
\mathrm{DIFF}=\mathrm{DUR}_{\text {June }}-\mathrm{DUR}_{\text {May }}
$$

The measurement of DIFF is complicated by several factors. First, some survey participants may be unemployed on both survey dates but report a much lower spell duration in the second interview because at some point between surveys they either found a job or stopped searching. Since there is no way of determining whether inconsistent reports with second-interview durations of less than five weeks are spurious, we report results which both include and exclude this group (DUR June

1 Between the May and June surveys which are the focus of our work, 4.43 months elapsed. 
from the calculations. Second, some respondents may appear to make inconsistent responses because they have been unemployed for so long that both duration values are coded as 99. Duration is recorded in a two-digit data field so that spells of more than 99 weeks are not reported exactly. However, this problem did not appear to be substantial: only $1.7 \%$ of the respondents whose durations did not change had reported "99" on the May survey, and a negligible fraction had May durations of between 96 and 98 weeks.

Summary statistics for DIFF are displayed in Table II. Table II-A shows calculations which exclude all individuals for whom DUR JNE $<5$, while the results in Table II-B include these respondents. Only one-third ( $31.8 \%)$ of the individuals in the match sample reported spell durations which differed by between three and five weeks. Nearly three quarters of the respondents made inconsistent claims about their unemployment experience, and over twenty percent reported no increase, or a decrease, in their spell duration. Thirty-seven percent of the sample reported unemployment spell durations in June which exceeded their May durations by more than five weeks, and many reported much longer spells. More than ten percent of our sample reported that the length of their unemployment spell had increased by over four months.

Workers who have experienced long spells of unemployment are particularly unreliable in reporting spell durations. We discovered this by dividing the sample into two groups. Individuals in Group I had reported being unemployed for at least 20 weeks in May; those in Group II had been unemployed for less than 20 weeks. The duration-difference calculations for these subgroups are also shown in Table II. Twelve percent of the long-spell individuals report the same duration both 
TABLE II-A

Monthly Differences in Reported Unemployment Spell Durations

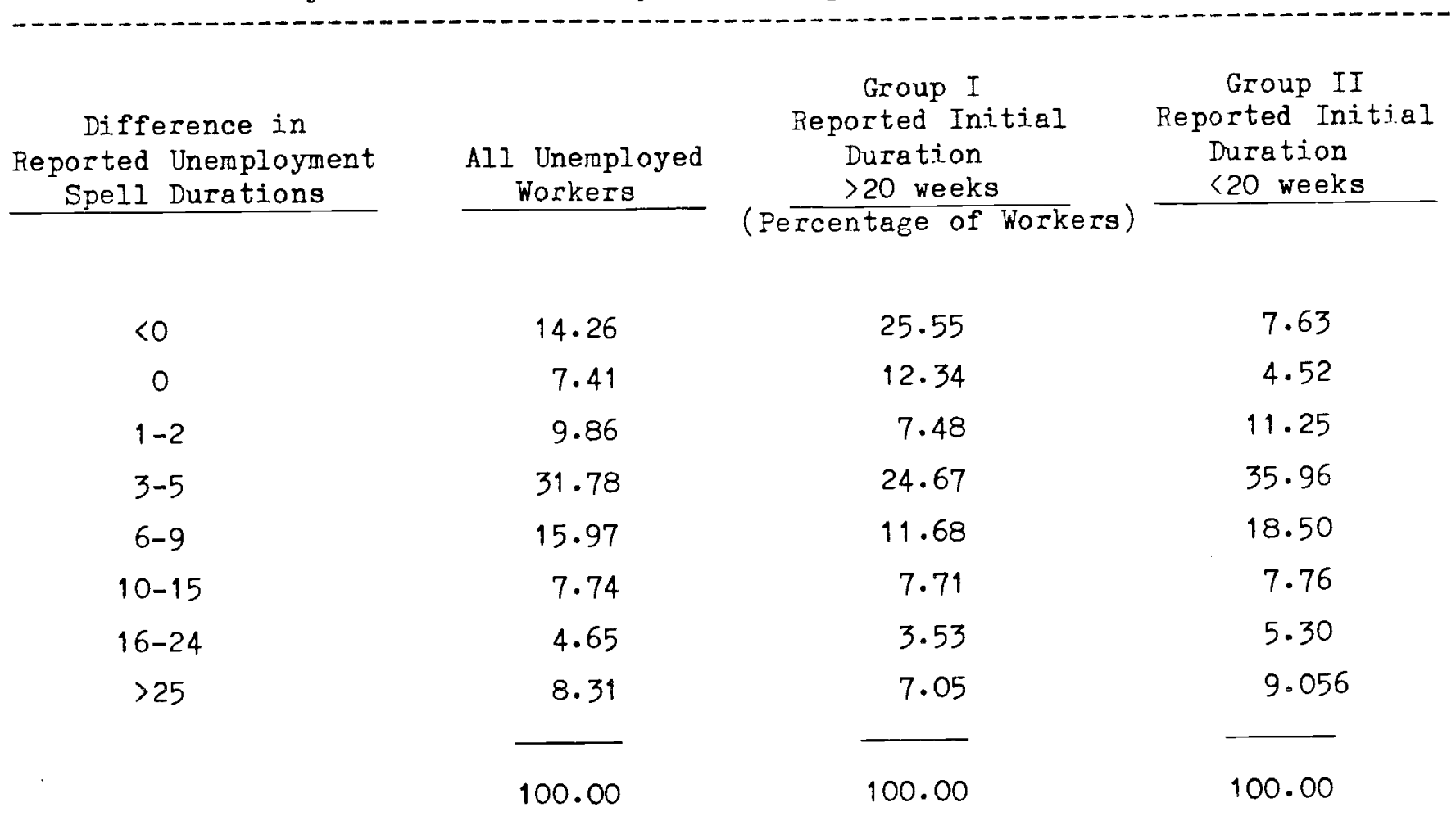

Notes: Calculations based on May 1976 CPS questionnaire participants who were classified as unemployed who were of more than 16 years of age, and who reported May unemployment durations of more than four weeks. The subsequent duration numbers are based on reported responses to the June 1976 survey. A total of 1227 individuals who were recorded as unemployed in May were reinterviewed, and found to be unemployed again in June. 


\section{TABLE II-B}

Monthly Differences in Reported Unemployment Spell Durations

\begin{tabular}{|c|c|c|c|}
\hline $\begin{array}{c}\text { Difference in } \\
\text { Reported Unemployment } \\
\text { Spell Duratjons } \\
\end{array}$ & $\begin{array}{l}\text { All Unemployed } \\
\text { Workers }\end{array}$ & $\begin{array}{l}\text { Group I } \\
\text { Reported Initial } \\
\text { Duration } \\
>20 \text { weeks } \\
\end{array}$ & $\begin{array}{l}\text { Group II } \\
\text { Reported Initial } \\
\text { Duration } \\
<20 \text { weeks } \\
\end{array}$ \\
\hline$<0$ & 19.62 & 29.29 & 14.60 \\
\hline 0 & 9.19 & 11.72 & 7.97 \\
\hline $1-2$ & 12.09 & $7 \cdot 11$ & 14.60 \\
\hline $2-5$ & 27.99 & 23.45 & 30.33 \\
\hline $6-9$ & 13.55 & 11.09 & 14.80 \\
\hline $10-15$ & 6.57 & $7 \cdot 32$ & 6.21 \\
\hline 16.24 & 3.94 & 3.76 & $4 \cdot 24$ \\
\hline$>25$ & 7.00 & 6.28 & 7.25 \\
\hline
\end{tabular}

Notes: Calculations based on May 1976 CPS questionnaire participants who were classified as unemployed, and were more than 16 years of age. A total of 1447 such individuals were available on the May-June match. 
months. 1 Only twenty-five percent added between 3 and 5 weeks to their initial reported spell length, and over one quarter of the Group I respondents claimed a shorter spell duration in June than in May. These findings indicate substantial variation in the reported unemploynent durations of survey participants experjencing ongoing unemployment spells.

Regression models can be used to determine those factors which are related to substantial aberrations in the reported spell durations. Table III reports regressions of duration differences on individual's demographic characteristics and reasons for unemployment. There are two equations in the table. The first equation was estjmated using reported duration differences as the dependent variable, while the second equation was estimated on data for which the outlying values of DIFF were "trimmed". Observations for which DIFF exceeded 25 weeks were replaced with 25 , and observations for which DIFF < -5 were replaced with -5 . Similar results obtain for both sets of data. The average value of the duration differences by reasons for unemployment are: job losers, 6.24, job leavers, 5.64, workers on layoff, 4.69, reentrants and new entrants, 7.74. These values are drawn from the "trimmed" regression; all are larger than the four-andthree-sevenths weeks which actually separated the two surveys. There is little evidence that demographic factors change reported duration differences. The one exception is teenage women, who appear to systematically underreport their duration increment. The reason for unemployment also has a large effect in predicting duration differences. Workers who are on layoff report differences which are up to two weeks less than those of other unemployed individuals while reentrants and new

\footnotetext{
1 Only a small fraction (1.7\%) of the no-change respondents were in the nochange category because they had been unemployed for more than 99 weeks in May. Ninety-nine weeks is the maximum spell duration which can be reported on the CPS questionnaire.
} 
TABLE III

Dependent Variable: Duration JUNE Duration $_{\text {MAY }}$

Independent

Variable

Constant

MI619

M2024

M2559

M60

W1619

พ2024

w60

RACE

$(1=$ nonwhite $)$

LOSER

LEAVER

LAYOFF

Rotation Group I

Rotation Group II

SSE

$\mathrm{R}^{2}$

No. of observations
Model without Outlier Ad justment

$$
9.12
$$

$(1.66)$

$$
-.18
$$

$(1.86)$

$$
-1.28
$$$$
(1.67)
$$

$$
\begin{gathered}
.68 \\
(1.37)
\end{gathered}
$$

$$
1.57
$$

(2.75)

$$
-7.29
$$$$
(2.64)
$$

$$
-.31
$$$$
\text { (2.13) }
$$

$$
-2.90
$$$$
\text { (3.50) }
$$

$$
-1.62
$$$$
\text { (1.61) }
$$

$$
\begin{aligned}
& \text { Model with Outlier } \\
& \text { Adjustrent }
\end{aligned}
$$

$$
\begin{aligned}
& 7.74 \\
& (.81)
\end{aligned}
$$

$$
-.83
$$

$$
-.43
$$

$$
\begin{aligned}
& .38 \\
& (.67)
\end{aligned}
$$

$$
.53
$$

$-2.93$

$-2.18$

(1.18)

$$
\begin{gathered}
.40 \\
(1.04)
\end{gathered}
$$

$$
-1.39
$$

$(1.71)$

$-4.47$

$(1.62)$

$-4.51$

(1.54)

$$
\begin{gathered}
.22 \\
(.78)
\end{gathered}
$$

$-1 \cdot 50$

$(.58)$

$-2.10$

(.78)

$-3.05$

(.75)

$-.01$

(1.15)

$-.30$

(.55)

$-1 \cdot 34$

(1.09)

$-.68$

(.54)

315623

75052

.022

.022

1227 
entrants have the greatest tendency to overstate duration differences.1

Besides knowing the average increment to the unemployment duration, we might be concerned about errors of any type, either overstatement or understatement. To analyze this issue, Table IV reports regressions explaining the absolute value of (DUR $\mathrm{JUNE}^{-}$(DUR MAY $\left.\left.{ }^{+} 4\right)\right)$. The reported cause of unemployment affects the error in reported durations in a significant and important way. Job losers are about two and one half weeks more accurate than the "control" group of re-entrants and new entrants. Job leavers are two weeks more accurate than the controls, on average, and persons on layoff have still smaller response errors. For individuals on layoff workers' errors are on average between three and six weeks less than the control and as much as three weeks less than either losers or leavers. The salary which the jndividual earned at his last job also has a statistically significant but economically small impact: a ten dollar per week rise in wages reduces an jndividual's predicted inconsistency by about one one tenth of a week. ${ }^{2}$

1 We also experimented by adding the individuals' reported May duration to the regression models. This had a substantial negative effect on the reported duration difference. However, it is difficult to determine whether this is genuinely the result of the longer-duration unemployed responding with smaller differences. An alternative explanation is that the finding is purely a statistical artifact. Conditional on a high reported May duration, the difference between the June and May durations is likely to be less than if the value of DUR May is low. This means that in a regression model for DIFF, DUR May will have a negative coefficient. This hypothesis also predicts that, by similar reasoning, DUR June should have a positive coefficient. Some support for this view was provided when we substituted DUR June in place of DUR May and observed a significant positive coefficient. Therefore, since the results appear spurious, we have not reported equations which include duration variables.

2 our equations also include control variables for the respondents' rotation group in the CPS. These variables, although reported in the tables, never proved statistically significant. Rotation Group I indicates individuals who particpated in the Survey in May, June, July, and August; Rotation Group II denotes those who participated only in May, June, and July. The omitted dummy variable for those who participated only in the May and June surveys. 
TABLE IV

Duration Error Equations

Dependent Variable: |DUR JUNE ${ }^{-D_{U R}}$ MAY $^{-4}$ |

$\begin{array}{ccc}\text { Independent } & \text { Model without Outlier } & \text { Model with Outlier } \\ \text { Variable } & \text { Adjustment } & \text { Adjustment }\end{array}$

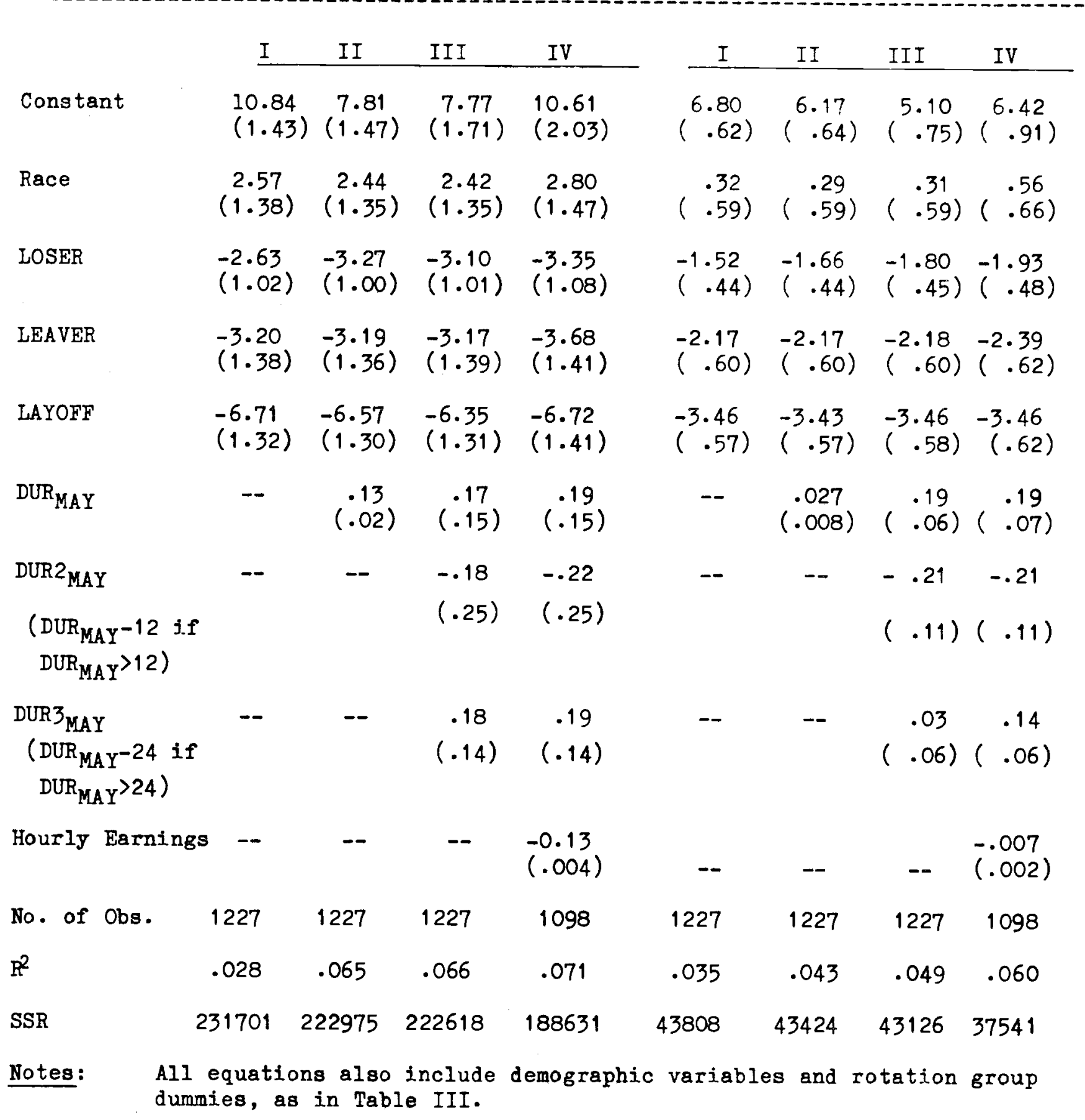


The most important finding is that the duration of the unemployment spell affects the consistency of the individual's responses. An additional month of unemployment increases the absolute value of the difference between the reported duration difference and "truth" (43 weeks) by about five days. However, the effect of duration is more complicated than this simple model suggests. We included three linear segments in specification III to capture the possibly different duration effects of short and long spells. The duration-related "error" in the spell length difference based on these regressions is calculated below for several different durations.

\begin{tabular}{|c|c|c|}
\hline Duration ( DUR $_{\text {May }}$ ) & Contribution of & DUR $_{\text {May }}$ to $\mid$ DIFF-4| \\
\hline O weeks & 0 & \\
\hline 6 weeks & 1.02 & weeks \\
\hline 12 weeks & 2.04 & weeks \\
\hline 20 weeks & 1.96 & weeks \\
\hline 30 weeks & 4.02 & weeks \\
\hline 50 weeks & 6.34 & weeks \\
\hline
\end{tabular}

Additional weeks of unemployment spell duration are particularly poorly reflected in responses of individuals who have been unemployed for a very long period. For spells lasting more than a year, the predicted absolute value of the response error is over six weeks.

Further evidence on the reported spell durations of "new entrants" to unemployment can be obtained by studying the individuals who were categorized as employed or NILF in May and became unemployed in June. Of those experiencing E-U transitions, seventy-six percent reported June spell durations of not more than four weeks. About eight percent of this newly 
unemployed group, however, reported durations of over 25 weeks after not more than four weeks of unemployment. Findings for the N-U transitors were similar: seventy-one percent reported spells of less than five weeks, but seven percent reported very long spells (>25 weeks). This latter category may comprise some U-NILF-U individuals.

III. The Distinction Between Unemployment and Not-in-the-Labor Force

A third, but closely related, problem of response error concerns the reported unemployment spell durations of individuals making labor market transitions. Forty-four percent of unemployment spells end when job-seekers choose to leave the labor force. ${ }^{1}$ However, there are frequent transitions between the states of unemployment (U) and Not in Labor Force (NILF). Of the individuals who were unemployed in May 1976 and for whom three consecutive CPS questionnaires were available, 81, or three percent, were reported as NILF in June and unemployed again in July. By comparison, 544 individuals (21 percent of the May unemployed sample) were reported as unemployed for three consecutive months.

An individual who leaves the labor force is technically considered to have completed his spell of unemployment. If at some later date he chooses to re-enter the pool of the unemployed to search for work, he begins a second unemployment spell. If survey respondents adhered to this convention, individuals who were out of the labor force in June would not report spell durations which exceeded four weeks. As the lower panel of Table V

1 This was calculated as $\frac{\text { Prob(transition from unemployment to NILF) }}{\text { Prob(transition from unemployment to employment or NILF) }}$ For further discussion of labor market dynamics in this framework, see Clark and Summers (1979). 
TABLE V

Reported Unemployment Durations:

Individual Experiencing Temporary Labor Force Wi.thdrawal

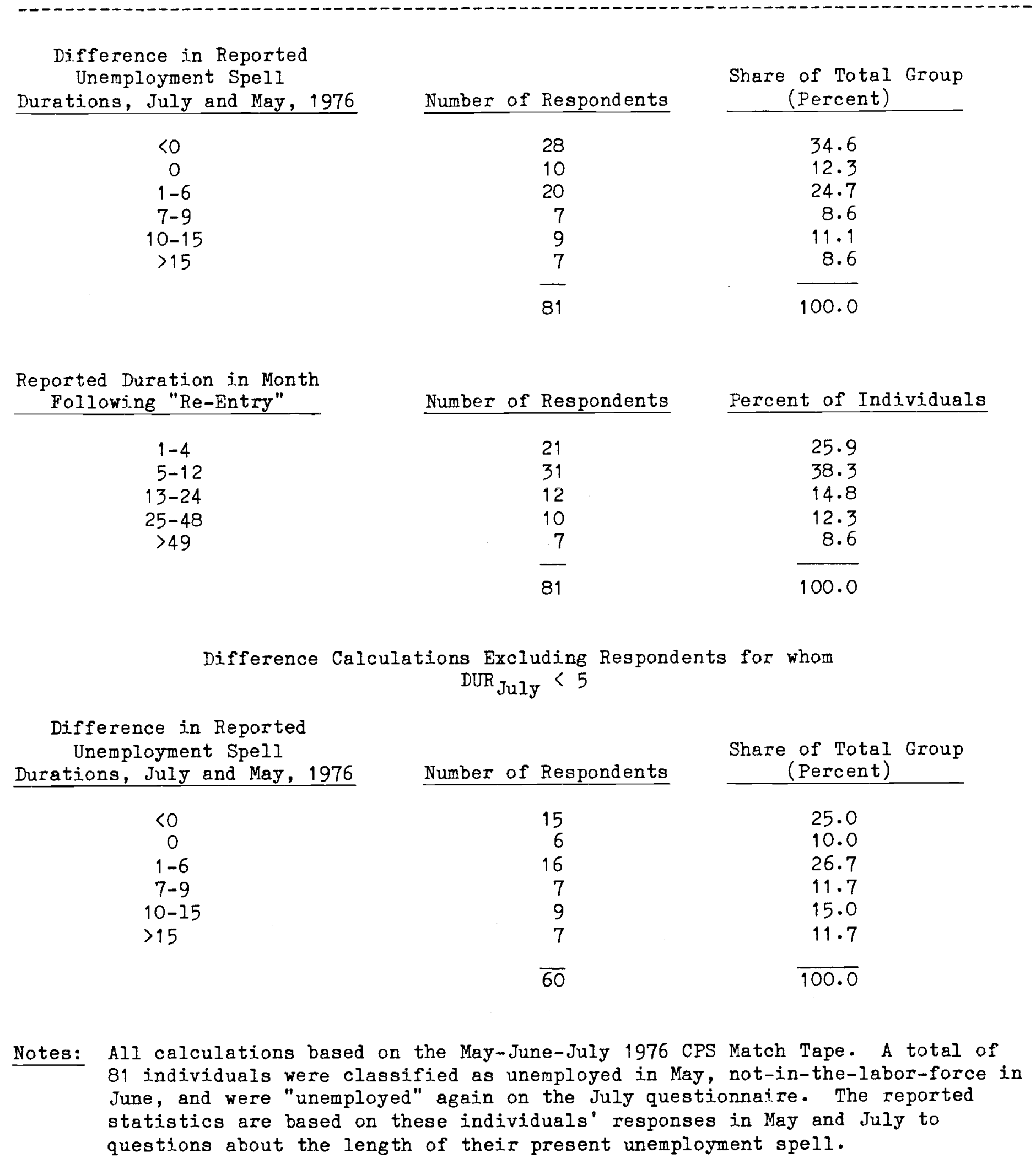


demonstrates, however, only twenty-six percent of the U-N-U survey respondents considered themselves to have begun new spells. One-third of the U-N-U group reported lower spell durations in the second survey, but this is not appreciably different from the fraction of shorter spells discovered in the one month match reported in Table II. However, it would also be incorrect to characterize the data as suggesting that time out of the labor force is treated as the equivalent of time spent unemployed. Less than thirty percent of the group added a full eight weeks to their reported May unemployment spell duration. When we focus on those individuals who did not report short spells ( $<5$ weeks) in July, the share of responses for which Dur July- DUR May is between seven and nine weks is only 12 percent.

About two thirds of unemployed individuals who are classified as experiencing $\mathrm{U}-\mathrm{N}-\mathrm{U}$ transitions appear to view themselves as in the midst of an ongoing unemployment spell. This supports the conclusion that there is a substantial amount of "hidden unemployment" and that for many U-N-U transitors, the state of "not-in-the-labor force" is functionally equivalent to unemployment. This emphasizes the ambiguity of current measures of labor market status, and helps to explain the strongly procyclical behavior of labor force participation.

\section{Reasons for Unemployment}

The match file also affords an opportunity for making inter-month comparisons of respondents' stated reasons for entering unemployment. Using the May-June Match file, we cross-tabulated the respondents' May 
"reason". with thej.r June "reason".I Table VI shows that only about seventy percent of the respondents cited the same reason for unemployment in both May and June. The correlation between the two responses is lowest for those originally reported as job leavers; only fifty-six percent of the May job leavers reported themselves as leavers again in June. Of those who changed classification, fiftyeight percent moved to the category of job loser and thirty-four percent became reentrants. The groups with the highest inter-month correlations were job losers, and new entrants: roughly eighty percent of the May respondents in these groups provided similar responses in the June survey. The largest inter-category movement was from layoff to job loser: thirty percent of those reported to be on temporary or permanent layoff in May reported themselves as job losers in June. There also appears to be a surprisingly large amount of movement between re-entrants and job losers.

The large incidence of reported changes from the layoff to the job loser category is of particular significance. Although the empirical importance of temporary layoff unemployment has been proclajmed by several authors, the evidence here suggests that its significance may well have been overstated. A natural interpretation of the large change in the responses of persons initially on layoff is that they realize that they cannot return to their original employer. If this interpretation is correct it implies that even the 9.2 percent of unemployment attributable to layoffs substantially overstates the proportion of the unemployed who will be able to return to their original employers.

\footnotetext{
I Job losers and leavers were categorized on the basis of the "why did...start looking for work?" question. Workers who explained that they were on permanent or temporary layoff in response to the question "why was...absent from work last week?" were classified as on layoff. New entrants were those non-leavers, non-losers who claimed either that (i) they had never worked at all, or ( $i i)$ they had never worked full-time for more than two consecutive weeks. Any worker who did not fall into any of these four categories was classified as a re-entrant.
} 
TABLE VI

Response Variation:

June Cause of Unemployment by May Cause of Unemployment

Reason for Unemployment (June)

(percentage of May respondents)

\begin{tabular}{|c|c|c|c|c|c|}
\hline $\begin{array}{l}\text { Reason for } \\
\text { Unemployment } \\
\text { (May) }\end{array}$ & $\begin{array}{c}\text { Job } \\
\text { Loser }\end{array}$ & $\begin{array}{c}\text { Job } \\
\text { Leaver }\end{array}$ & Lay off & $\begin{array}{c}\text { New } \\
\text { Entrant } \\
\end{array}$ & $\begin{array}{c}\mathrm{Re}- \\
\text { Entrant } \\
\end{array}$ \\
\hline Job Loser & 82.1 & 5.2 & 6.0 & 0.7 & 6.3 \\
\hline Job Leaver & 25.1 & 56.6 & 1.7 & 1.7 & $14 \cdot 8$ \\
\hline Layoff & 30.6 & 1.9 & 63.6 & 0.0 & $4 \cdot 3$ \\
\hline New Entrant & 0.6 & 1.8 & 0.6 & 79.9 & $17 \cdot 2$ \\
\hline Re-Entrant & 17.5 & 9.5 & 0.9 & 6.2 & 66.0 \\
\hline $\begin{array}{c}\text { Share of June } \\
\text { Survey }\end{array}$ & $44 \cdot 5$ & 11.3 & 11.8 & 10.9 & 21.5 \\
\hline
\end{tabular}

Notes: Calculations performed using the 1497 records on the May-June 1976 CPS match tape for which the respondent was unemployed in both May and June. The calculations show the percentage of, for example, May Job Losers who also reported themselves as job losers in June (= $82.1 \%)$. 


\section{Conclusions}

These results suggest the unreliabjlity of individual responses to fundamental parts of the monthly CPS questionnaire. They buttress the evidence from Reinterview Surveys suggesting that a great deal of misreporting or misrecording takes place. While information of the type presented here cannot be used to evaluate the bias in CPS responses, it does suggest that any sort of behavioral change is likely to be greatly overstated because of response error.

This analysis of the Current Population Survey sheds light more generally on problems of response error in survey research. For a number of reasons, the CPS is likely to generate more accurate and consistent responses than other sample surveys. The CPS questions ask only about recent behavior, rather than behavior over the course of a year or longer interval. More safeguards are used to ensure reliability than in most other studies of labor market behavior. To a greater extent, CPS questions probe objective behavior rather than subjective intent. Our focus on the CPS is motivated by j.ts widespread use by researchers and policymakers and the availability of data necessary for consistency checks.

We believe that our findings suggesting the need for caution in performing statistical analysis of these data are applicable to other surveys of labor market behavior, though more research on this question would be valuable. Especially when investigations focus on changes, errors in variables problems are likely to be enormous. Unfortunately, most of the methods used to examine aspects of dynamic labor supply behavior are not at all robust with respect to errors in variables. Future research should examine more thoroughly the causes of misreporting and examine alternative techniques for developing consistent data. In the meantime statistical techniques for adjusting data, and for 
estimating in the presence of errors in variables, should be developed. Work on this task is underway. 


\section{REFERENCES}

Bureau of the Census (1963). The Current Population Survey Reinterview Program: Some Notes and Discussion. Technical Paper No. 7 (Washington, D.C.: Government Printing Office).

Bureau of the Census (1968). The Current Population Survey Reinterview Program: January 1961 through December 1966. Technical Paper No. 19 (Washington, D.C.: Government Printing office).

Clark, Kim B. and Lawrence H. Summers (1979). "Labor Market Dynamics and Unemployment: A Reconsideration", Brookings Papers on Economic Activity, 1:1979, 13-60.

Flinn, Christopher J. and James J. Heckman (1982). "Are Unemployment and Out-of-the-Labor Force Behaviorally Distinct States?" NBER Working Paper No. 979, Cambridge, MA.

Graham, Dorcas W. (1974). "Estimation, Interpretation, and Use of Response Eтrот Measurements", unpublished paper, U.S. Commerce Department.

Poterba, J.M. and L.H. Summers (1983a). "Spurious Transitions and the Gross Flows Data", in preparation.

$$
\text { (1983b). "A Multinomial Logit Model with }
$$

Errors in Classification". Mimeo.

Woltman, Henry and Irv Shreiner (1979). "Possible Effects of Response Variance on the Gross Changes Data", unpublished Bureau of Census memo, May 11, 1979. 